\title{
El orden negado Notas sobre la corrupción de las fuerzas represivas en Iberoamérica
}

\author{
Fernando Escalante Gonzalbo*
}

$\mathrm{N}$

o es frecuente que la corrupción se proponga como tema de análisis político. Mucho menos, desde luego, que se le asigne un lugar privilegiado en el proceso de la vida pública; como forma degenerada de las prácticas políticas y administrativas, se entiende que ha de estudiarse como un epifenómeno, subordinado a las formas y relaciones abiertamente estatuidas. Y no habría nada que objetar, en principio, a esa versión, si no fuera porque la corrupción es uno de los datos más evidentes de la vida política iberoamericana.

En mayor o menor medida, según países, épocas o sectores del aparato estatal, la corrupción es una constante; con frecuencia cabrá decir que es la norma, antes que la desviación. Se puede aceptar que haya una cierta distancia entre la percepción social y los hechos mismos, pero eso no hace sino añadir otro tema más al análisis: la visión social de los funcionarios y de los agentes del orden público. En todo caso, la suspicacia colectiva, por más que pueda estar acentuada por un prejuicio, tiene buenas razones para fundarse.

De tal suerte, acaso tenga sentido proponer que la dinámica de la corrupción sea un factor decisivo de la política iberoamericana, tanto o más que las formas jurídicas del orden.

Como punto de partida anoto una definición sumaria de corrupción: entiendo por tal el uso de las facultades y atribuciones de cualquier cargo de autoridad pública para servir a fines particulares, en contravención de las disposiciones legales. El término comprende, pues, desde la asignación fraudulenta de contratos públicos hasta las actividades clandestinas de miembros de las fuerzas represivas, a sueldo de políticos o empresarios, pasando por todo tipo de usos administrativos y judiciales.

Hace falta insistir, para evitar interpretaciones simplistas, en que la corrupción no es un problema moral, sino político; no me interesa como tema de culpa o inocencia individual, sino como condición de una estructura. Y con ello tampoco pretendo que sea un estigma, parte de una herencia cultural insalvable: es un producto del orden económico y político de nuestros países, ni más fatal ni menos reformable que la dependencia o la desigualdad.

Escoger como eje del análisis a las fuerzas represivas -ejército y cuerpos policiacos - no es arbitrario. La corrupción aparece por igual en el resto del aparato estatal, pero, por su función, en ningún otro cuerpo es más apreciada la disciplina, y ninguno tiene tan a mano la transgresión impune de la legalidad. Son, por decirlo así, una instituciónfrontera del Estado, cuya participación política las hace, además, un referente obligado para entender la relación entre la dinámica social y

* Quiero agradecer el generoso apoyo que he recibido de don Gregorio Selser para la investigación de que este ensayo forma parte; sobra decir que no tiene él ninguna responsabilidad por los disparates que pueda haber en mi texto. 
la estructura estatal en Iberoamérica.

Probablemente el desinterés a que he aludido, la escasa atención que recibe el tema, sea el resultado de un prejuicio racionalista, que quiere explicar a la sociedad por intereses de clase y estructuras políticas, asumiendo que la corrupción tiene un lugar apenas marginal en los grandes procesos históricos. Yo no pretendo que sea la clave de nuestra organización social, pero sí creo que su incidencia sobre ésta es mayor de lo que se ha supuesto.

En las notas que siguen quiero esbozar una serie de hipótesis sobre las condiciones que prohíjan la corrupción de las fuerzas represivas, la función social que puede cumplir la manera en que afecta al orden político. No intento ser concluyente: éste es apenas el esquema argumental de un trabajo de investigación todavía inconcluso. Para dar mayor agilidad al texto, y para subrayar su carácter hipotético, tentativo, he prescindido de referencias teóricas y documentales.

Para explicar la corrupción de las fuerzas represivas como fenómeno permanente, estructural, es preciso describir, por una parte, las condiciones que la hacen posible, y por otra, las tendencias que la hacen probable. En un esquema muy burdo podría decirse que las condiciones de posibilidad son, centralmente, el acceso a un mercado de servicios clandestinos o ilegales y una plausible impunidad de tales prácticas; además, las tendencias que hacen probable el recurso a la corrupción son una cultura política que menosprecia la legalidad y la vida cívica, y una estructura social que alienta la obtención rápida de privilegios. ${ }^{1}$

Ciertamente, la corrupción tal como hoy la entendemos supone también, como condición general, una particular forma de Estado. Supone, en primer término, una delimitación legal de la autoridad, en un sistema jurídico que defina el orden como representación del bien común, y que deslinde un ámbito público de otro privado. Supone, en segundo lugar, una organización racional, burocrática, del poder público, donde todas las funciones se encuentran legalmente establecidas y administrativamente ordenadas.

Así, la corrupción no afecta - no sólo- a los ciudadanos, sino al propio Estado como institución. Si el orden jurídico fuese subordinado a los intereses particulares hasta ser del todo inoperante, la forma estatal sería no más que un simulacro, incapaz de reproducir el orden social.

El extremo imaginable es, entonces, la desarticulación del Estado que, paradójicamente, dejaría sin sentido a la noción misma de corrupción. Sin embargo, hay que llamar la atención sobre un punto: no toda práctica del aparato estatal contraria a la legalidad es, llanamente, corrupción; hay que contar siempre con un desfase - más o menos importante- entre el orden jurídico y el orden político real.

La razón de Estado es un límite impreciso, donde la política no se conforma con la legalidad, pero confirma la vigencia de la institución estatal como eje y frontera de lo político.

Dada la forma estatal esbozada, la corrupción aparece como una autonomía anormal en la práctica de los agentes públicos. Por orgánica que sea, por generalizada que sea, siempre implica una orientación ajena al interés institucional del Estado. Al mismo tiempo, por

${ }^{1}$ Por supuesto, Ja corrupción aparece también en sociedades con una cultura legalista, pero en ese caso debe explicarse por otros factores de la moralidad pública $-y$ privada-, que dificilmente le dan un carácter estructural. 
rutinaria que sea la violación de la ley, siempre será ésta necesaria como condición previa para el mercado de la corrupción: donde no hay reglas, no hay tampoco necesidad de comprar la buena voluntad de los funcionarios, ni posibilidad de venderla.

Por su función y su estructura interna, las fuerzas represivas tienen una superioridad fáctica sobre el resto de los actores políticos que, unida a la secular inestabilidad de las estructuras cívicas del Estado, hace particularmente insistente su intervención en la vida social fuera de la legalidad. De hecho, el recurso de la violencia ilegal es una necesidad del orden político que no podría, con frecuencia, mantenerse sólo por las vías jurídicamente establecidas.

En principio, la represión al margen de la legalidad es producto de la necesidad política; sin embargo, sus consecuencias en el largo plazo son difícilmente manejables. Conforme más deba reposar la reproducción del orden sobre las fuerzas represivas, mayor será la autonomía que adquieran éstas, y más difícil será poner en práctica mecanismos civiles de control. Todo esto es un lugar común, pero hay que insistir en ello.

La represión clandestina tiende necesariamente a crear su propia dinámica, hasta que la clase política y las fuerzas represivas se encierran en un círculo donde el chantaje recíproco es un vínculo más eficiente que la legalidad o el proyecto estatal. Autonomía e impunidad van de la mano, como condiciones del trabajo sucio que necesitan las instituciones.

Ahora bien, esos servicios clandestinos, aun siendo ideológicos, exigen una retribución tangible, capaz de asegurar su continuidad y, por supuesto, su discreción. Los Estados iberoamericanos han pagado la preservación de su orden político con prebendas y privilegios corporativos, o con la concesión de feudos y negocios más o menos ilícitos a sus fuerzas armadas.

De tal forma, en la represión clandestina o ilegal se trama uno de los nudos de la corrupción. En la práctica, sin embargo, es difícil distinguir entre esa violencia que alega el amparo de la razón de Estado y la violencia privada, al servicio de políticos, terratenientes o empresarios. En algunos casos, las guardias blancas o escuadrones de la muerte son sólo tolerados por las fuerzas del orden público, y en otros son los propios miembros de los cuerpos de seguridad los que aparecen -0 desaparecen- bajo siglas de grupos de ultraderecha o como simples matones a sueldo.

Descontando los casos en que esa simulación es parte de una estrategia planeada desde el Estado, no es infrecuente que tal aparato de intimidación sea obra de particulares. Habría mucho que decir sobre esa participación de la violencia privada en la preservación del orden, pero de momento me interesa sólo subrayar el vínculo que representa entre los intereses privados y las fuerzas del orden público. Indispensables para la clase política tradicional que teme ser rebasada por la participación popular, las fuerzas represivas son necesarias también para apuntalar las formas del poder privado.

Políticos y propietarios producen los cuerpos armados que necesitan; difícilmente serían utilizables unas fuerzas represivas con conciencia republicana y legalista; antes al contrario, es preciso que se presten a intervenir fuera del orden jurídico, que sean instrumento de una violencia selectiva, clandestina, silenciosa. Se convierten así en una sin- 
gular clientela capaz de negociar la violencia que ejerce, a cambio de garantías de impunidad y fuentes constantes de beneficios, legales o no.

Esa producción privada del orden no puede prescindir, sin embargo, de la estructura jurídica del Estado como referente social capaz de negociar la violencia que ejerce, a cambio de garantías de impunidad y fuentes constantes de beneficios, legales o no.

Esa producción privada del orden no puede prescindir, sin embargo, de la estructura jurídica del Estado como referente social capaz de convocar una cierta legitimidad. En el mismo sentido, la legalidad abre los espacios de corrupción -puesto que, con las prohibiciones crea también las ganancias-y permite mantener a las fuerzas represivas en una condición subordinada. Al transgredir ciertas normas, el mercado de la corrupción crea sus ganancias gracias a la existencia del sistema jurídico completo.

De tal suerte, las fuerzas represivas se convierten en una forma de intermediación política y económica entre el orden jurídico y el real. Una forma de intermediación parasitaria que reproduce intereses propios. Casi sobra decir que esa función recae sobre el o los cuerpos que tengan una mayor presencia cotidiana, mayores responsabilidades de control social.

En esas condiciones, tiene poco sentido plantear el tema de los controles civiles de la actividad militar o, en su caso, policiaca: de un lado, es el propio carácter incompleto o inoperante de las instituciones cívicas lo que prohíja la autonomía de las fuerzas represivas; del otro, por paradójico que suene, la supervivencia de las precarias estructuras estatales necesita esas prácticas informales de control. Sea por impotencia, por temor o por conveniencia, el hecho es que la clase política no está dispuesta a alterar radicalmente estos patrones.

Hay que contar, desde luego, con la incapacidad de las instituciones civiles para enfrentar, no ya un golpe de Estado, sino el desorden que podría derivarse de un intento de ruptura; sin embargo, el factor decisivo para garantizar la impunidad de la corrupción es la complicidad. La corrupción no es sólo el resultado de la inmoralidad individual, no es producto de una voluntad unilateral; es, con todas sus consecuencias, un mercado.

Es una forma de intercambio que, en sus extremos, puede adoptar el carácter de un chantaje, pero que en su definición básica se apoya en la reciprocidad. De tal modo, conforme más amplio sea el círculo de quienes se benefician con ella, mayor será su inercia y su solidez.

Esto, la dimensión de la red de complicidades, parece elemental; y lo es, pero tiene consecuencias sobre las que vale la pena reparar. En primer lugar, la extensión del mercado exige, para consolidarse, hacer corporativo el negocio; en segundo lugar, para mantener su crecimiento, su dinamismo, necesita el acceso a flujos crecientes de dinero.

El espíritu de cuerpo de las fuerzas represivas tiene, y ha tenido, una importancia inequívoca para la política iberoamericana; en el caso de la corrupción, tiene también una función sobresaliente. En principio, desde luego, la mecánica corporativa es garantía de impunidad, es un sistema de protección que no puede atacarse sin provocar una respuesta cerrada; pero también la conciencia corporativa es condición y consecuencia de la ampliación y estructuración del mercado de la corrupción.

La otra condición de su dinamismo, el acceso a flujos crecientes de dinero, es fundamental porque se convierte en un mecanismo de acele- 
ración cuyas consecuencias son impredecibles. Es obvio que los grupos locales de poder y las empresas multinacionales cuentan siempre con recursos para mantener un orden político a su medida: la corrupción de las fuerzas represivas ha sido tradicionalmente negocio de caciques y propietarios, cuando no de las empresas necesitadas de algún ajuste informal en la legislación o los mecanismos de control social. Sin embargo, en situaciones especiales, el ingreso masivo de recursos altera las formas de relación vigentes, ampliando el sistema de la corrupción.

Los ejemplos sobran. Cuando la movilización masiva pone en riesgo el orden y es preciso intensificar la represión clandestina, han de aumentarse parejamente los recursos destinados a mantener la lealtad de las fuerzas represivas. Cuando una dictadura militar, o incluso un gobierno civil, necesita protegerse de plausibles intentos golpistas, puede conceder feudos de corrupción para afirmar su posición.

Dos casos, empero, merecen una atención especial porque señalan la intervención de la dinámica internacional en los sistemas de corrupción y porque la magnitud de sus recursos los hace, prácticamente, incontrolables: la ayuda militar norteamericana y el tráfico de drogas.

Una característica fundamental -y por otra parte evidente- del dinero de la corrupción es que se trata de un "dinero silencioso". El éxito del intercambio depende, básicamente, de la discreción que, al mismo tiempo, protege a las dos partes involucradas en la transacción. En consecuencia, si los fines o el origen del dinero son directamente ilícitos o, at menos, inconfesables, el mercado queda seguro.

Así, pues, la presión exterior para alterar decisiones públicás necesita particularmente esa discreción, lo mismo que las actividades consideradas, en el orden jurídico internacional, delictivas. Hay una larga y conocida tradición de pagos irregulares de empresas multinacionales para asegurar sus beneficios fuera de competencia o al margen de la ley; la capacidad financiera, los recursos y la necesidad de discreción son mayores aún cuando se trata de intereses gubernamentales, o de organizaciones multinacionales de delincuencia.

Hay que tener en mente que la necesidad de evadir el orden jurídico no es sólo de los grupos locales. No es infrecuente que la política hemisférica de los Estados Unidos requiera los servicios más dispares de las fuerzas armadas iberoamericanas; y no es infrecuente tampoco que los pague con paquetes de ayuda militar cuyo destino y monto real rara vez dejan de ser secreto de Estado. La ampliación de la corrupción que esto trae consigo no hace sino confirmar la función subordinada, casi de carácter cipayo, de los cuerpos represivos que reciben la ayuda.

El negocio del narcotráfico es, para estos efectos, casi por completo transparente. Únicamente habría que subrayar que no se trata de algo nuevo, ni demasiado sorprendente. Para entenderlo sería preciso reconocer su incidencia sobre economías estructuralmente deformadas, su función política en la producción de un orden alterno y su papel en la estrategia de los Estados Unidos. La participación de las fuerzas represivas en el mercado de drogas es una consecuencia lógica del orden que las ha formado, y no una aberración insólita.

Pero todavía hay que señalar otra condición de posibilidad, de acceso a fuentes de beneficios silenciosos desde la impunidad: el golpe de Estado. Incluso si las razones que impulsan la toma del poder son, en principio, puramente ideológicas para la oficialidad superior, la situación que crea su ocupación del espacio político abre un margen considerable para la corrupción, e incluso la propicia. El acceso a los 
fondos y decisiones públicas, en una situación anómala, unido a la impunidad general que se produce, es condición sin duda favorable; si a eso se le suma que la estabilidad frente a un ejército pretoriano que ya asume, abiertamente. funciones politicas ha de pagarse, de algún modo, con privilegios. el cuadro está casi completo. La evidencia histórica dice el resto.

Las tendencias que hacen probable el recurso permanente a la corrupción provienen de una particular cultura política, de una forma precisa de la moral social. Importa insistir en que no se trata de un problema individual, sino del orden social; frente a ello, los intentos, más o menos sinceros, de control jurídico o administrativo tienen un efecto bastante limitado: apenas transforman el espacio de los intercambios irregulares, sin alcanzar a suprimirlo.

No sobra la acotación de que una reforma de la moral social ha de pasar por una reforma del orden político.

En una frase, la cultura política iberoamericana tiende a confirmar el escepticismo generalizado hacia las formas institucionales del poder público. En ese marco, el desarrollo de un interés corporativo de las fuerzas represivas no sólo margina, sino que se enfrenta directamente a la lógica institucional del Estado. Las funciones extraoficiales que se les asignan cierran, así, un círculo, generando una inercia de autopreservación de los privilegios adquiridos.

El descrédito de la institución estatal tiene motivos muy diferentes cuando se trata de comunidades campesinas, obreros sindicalizados, funcionarios públicos o grandes propietarios; sin embargo, la escasa eficacia histórica de las formas civiles de la política está a la vista para todos. La incapacidad de la clase política para mantener una hegemonía en torno a formas legales, cívicas y partícipes del dominio es un dato, explicado una y otra vez desde cualesquiera puntos de vista políticos, pero es un dato.

En la versión de los cuerpos represivos, la fragilidad del orden politico asume, las más de las veces, el carácter de una justificación de sus tareas sucias, cuando no es el andamiaje retórico del golpe de Estado. Esa ideologización de sus funciones irregulares, repetida machaconamente, no es sólo para el consumo externo: configura y refuerza el espíritu de cuerpo, y funciona como coartada moral para sus miembros.

Por ahora, el problema de la honestidad de tal creencia, de la convicción que la sostenga, puede quedar a un lado. Cabe suponer que la asimilación del discurso sea diferente entre la oficialidad y la tropa, o que las actitudes hacia él varien de un ejército a otro; pero, en todos los casos, es un referente para fraguar la identidad corporativa que legitima, de algún modo, su desprecio hacia la legalidad.

La insistente ideación de sus tareas excepcionales confirma una suerte de conciencia de superioridad que facilita la alteración de su función institucional. De ahí a la venta de sus servicios, al uso patrimonial de su capacidad de violencia, hay sólo un paso. La prepotencia no es un dato sicológico, sino una condición estructural.

A la certeza de ser políticamente necesarios, casi intocables, se une el soporte adicional de la conciencia de cuerpo: de un lado, la moral corporativa funda su eficacia en la valoración de las características privativas del grupo, centralmente la disciplina y el ejercicio de la violencia; del otro, el enfrentamiento práctico con la sociedad confirma la convicción de su superioridad por factores menos etéreos, 
como la capacidad de fuego o la organización.

Ciertamente, se trata de factores imponderables, pero cuya dinámica es, con todo, reconocible. En condiciones en que la intervención ilegal de las fuerzas represivas es políticamente necesaria, donde la impunidad está, por tanto, casi asumida de antemano y el margen de acción autónoma se amplía, la conciencia corporativa y la prepotencia apenas consolidan las tendencias que apuntan hacia la corrupción. Más aún si consideramos que, en tal orden de cosas, una convicción legalista e institucional resultaría amenazadora antes que funcional.

En todo esto asumo una condición de fondo que raras veces ha sido explicitamente propuesta: la radical falta de solidaridad que prevalece entre los diversos sectores de las sociedades iberoamericanas. Las trampas de lealtades y apoyos recíprocos se producen en espacios bien delimitados, o entre grupos capaces de identificarse positivamente. Lleva en ello su parte la formación de una moralidad pública híbrida y, sobre todo, una radical desigualdad en las condiciones materiales de vida, que hace inimaginable la comunidad de intereses prácticos.

La carencia de solidaridad mantiene una distancia definitiva entre las elites y las masas populares, y casi legitima, por omisión, cualquier forma de enriquecimiento individual. Cabe pensar que el estricto apego a la legalidad y el respeto hacia las formas republicanas y democráticas no alteraría demasiado el escepticismo general ante el orden, pero está fuera de duda que la corrupción aumenta las distancias, bloqueando cualquier posible intercambio democrático.

La virtual invalidación de la ley hace inoperante la única mediación formal, previsible entre la autoridad y sus súbditos. Ni por las condiciones materiales mínimas, ni por las normas establecidas puede constituirse lo público como espacio homogéneo de definición del interés común. Así, la intermediación parasitaria de los cuerpos represivos subraya la enajenación política de la mayoría de la población, reproduciendo un orden que se acomoda — sin importar la legalidad-al servicio de intereses particulares.

Sumamos, pues, el desprecio hacia la legalidad, la prepotencia del espíritu de cuerpo, la no solidaridad social, la inexistencia del espacio público como tal, y lo que es prácticamente una legitimación cultural de la ambición como eje de la vida moral. Pero tal vez el factor decisivo con que haya que contar hoy sea la inercia de la corrupción, la tendencia a la autoperpetuación de ese mercado subterráneo.

Para consolidarse, el tráfico de dinero silencioso y servicios informales debe ampliarse y, sobre todo en los cuerpos represivos, ordenarse a partir de principios jerárquicos y responsabilidades compartidas: en una palabra, debe hacerse orgánico. El interés corporativo interviene aquí para normalizar y cohonestar el ejercicio de la corrupción, pero también crea una dinámica autónoma, una red de intereses que buscan, necesariamente, su permanencia.

El sistema de concesiones requerido para afirmar el orden real termina por ser una exigencia y, no pocas veces, una nueva amenaza.

Para comprender la corrupción de las fuerzas represivas iberoamericanas hay que situarse en una posición peculiar: hay que reconocer que los dos polos del análisis político, el Estado y la sociedad civil, carecen de consistencia. En consecuencia, el orden jurídico, que prefigura una organización legal y burocrática del poder y una forma cívica de la 
política, es un referente precario para las prácticas cotidianas.

La legalidad no puede tener el carácter imperativo de una norma vigente; antes bien, aparece como una figura equívoca: a veces promesa o meta, ejemplo, límite o incluso amenaza. El orden político no se acomoda a las formas legales, y se reproduce por otras vías. Un cierto margen de ilegalidad en la actividad estatal es, más que funcional, indispensable para evitar que el patente desfase entre ambos órdenes desemboque en la confrontación, o para prevenir la quiebra institucional que provocaría, paradójicamente, el riguroso funcionamiento del sistema jurídico.

La imposible constitución de lo público como espacio de participación ciudadana perpetúa formas de la moralidad ajenas a la cultura cívica: formas patrimoniales, corporativas, comunitarias, que sostienen y estructuran el orden informal. En ese sentido, la corrupción de los cuerpos represivos responde al carácter incompleto -o inviabledel orden cívico: los grupos dominantes necesitan disponer de un aparato de violencia flexible, subordinado y comprometido - por razones prácticas-con la defensa de un sistema de privilegios.

Pero importa insistir en que no es ésa una práctica degenerada o una excrecencia impensada del orden institucional: es un factor decisivo para la constitución de lo político. Sin la corrupción de las fuerzas armadas y los cuerpos policiacos no podría haberse producido históricamente la forma estatal de dominio, ni podría mantenerse el orden político vigente.

Sin embargo, si es necesario aceptar esa intermediación parasitaria de las fuerzas represivas, también lo es permitir el uso de la violencia para promover intereses particulares: la participación privada en la producción del orden. Las formas patrimoniales se perpetúan a costa de la racionalidad estatal, y la autonomía forzada de los cuerpos armados desemboca en una suerte de feudalismo de la violencia para uso particular.

En el extremo hay, ciertamente, una disyuntiva entre Estado moderno y corrupción, pero acaso sea preciso pensarla no a partir de una legalidad deformada, sino del orden político vigente. El problema no es, acaso, que nuestros sistemas juridicos sean inoperantes, sino que nuestro orden político persiste bajo estas formas, y gracias a ellas. 